\title{
Performance Prediction of a Turboshaft ENGINE BY USING OF ONE DIMENSIONAL ANALYSIS
}

\author{
Siamak Hosseinzadeh $^{1 *}$, Ramin Ghasemiasl ${ }^{2}$, Meghdad Rahimi Galogahi ${ }^{3}$, Amin \\ Bahrami $^{4}$ \\ ${ }^{1,2}$ Department of Mechanical Engineering, West Tehran Branch, Islamic Azad \\ University, Tehran, Iran \\ Hoseinzadeh.siamak@gmail.com, info@ghasemiasl.ir \\ ${ }^{3}$ Department of Mechanical Engineering, Islamic Azad University, Behshahr Branch, \\ Mazandaran, Iran \\ rahimi meghdad@yahoo.com \\ ${ }^{4}$ Department of Mechanical Engineering, University of Science and Technology, \\ Tehran, Iran \\ aminbahrami 87 @yahoo.com
}

\begin{abstract}
Performance estimation of the axial flow gas turbines under variety of operating conditions like different speeds and pressure ratios has been hampered by lack of reliable experimental data and experiments cost. Simulation of gas turbine is a simple way to reduce testing costs and complexity. Onedimensional (1D) Simulation is a simple, fast and accurate method for performance prediction of turbine with different geometries. In this approach, inlet flow conditions and turbine geometry are known and by considering loss model, the turbine performance characteristics are predicted. In following work, that is based on one-dimensional modelling method, after the presentation of solution algorithm by trial and error method and introduction of different loss models for modelling, this method were examined for a turbo shaft engine and compared with experimental results. Comparison of the results with experimental data shows so good adaptation. Also according to these results, Kacker and Okapuu's developed model gave the closest results to the reference data.
\end{abstract}

\section{Keywords}

One-dimensional (1D) Simulation; Axial flow turbine; Total loss coefficient; Loss model; Performance curve

\section{INTRODUCTION}

Gas turbines have an important role in power generation and propulsion units and day to day with technology progress and increase the efficiency and performance, their utilization rises in aerospace and electricity generation plants and Power Generation systems [1].

Due to the very wide scope that exists for gas turbines, must show accurate and reliable performance in the vast range of environment temperature, pressure and also flight Mach and rotational speed.

Because of the complex flow and component interaction in modern gas turbine engine, these engines require extensive testing to validate performance and stability, but such testing has high costs [2]. Modelling and simulation of gas turbine engines are one way to reduce testing costs, and provide fidelity. Meanwhile, one-dimensional modeling is a simple and fast method due to the performance prediction and optimization of initial design. 


\section{Principles of One Dimensional Analysis}

Nowadays different computational and modeling methods are needed for simulating and optimizing turbomachines in order to design turbines more effectively and efficiently. Among these approachs, one-dimensional modeling is a simple and fast method for obtaining gas turbine performance condition. In this method, the averages of aerodynamic and thermodynamic properties are considered on midstream line.

In the present research the principles of flow analysis in turbine are based on continuity equation, energy equation, state relation for a perfect gas and isentropic relation over every blade row, that are the basic equations for one-dimensional modeling.

It worths noting that usage of modeling through the mentioned method has specific importance that the following features can be pointed:

1-Much less information is required from the turbine geometry.

2- In this method, computational volume is much less than other methods like CFD [2, 3, 4].

\subsection{One Dimensional Modelling by Using of Suggested Algorithm}

The suggested algorithm is based on flow field equation in turbine blades.

By applying the continuity equation on stator outlet section and replacement of Mach number relation in it, and by using other base equations, the dimensionless mass flow rate equation will be obtained by considering the losses term as $[1,5]$.

$\frac{m \cdot \sqrt{\frac{R T_{0}}{\gamma}}}{A_{\text {out }} P_{0}}=\sigma \cos \left(\alpha_{\text {out }}\right) M_{\text {out }}\left(1+\frac{\gamma-1}{2} M_{\text {out }}^{2}\right)^{\frac{\gamma+1}{2(1-\gamma)}}$

It can be seen that the left hand side of this equation is a function of the mass flow, m., the outlet flow area, $\mathrm{A}_{\text {out }}$, the stagnation temperature, T0, and the stagnation pressure, $\mathrm{P} 0$. And the right hand side is a function of the outlet Mach number, $\mathrm{M}_{\text {out }}$, and outlet flow angle, $\alpha$ out. The special symbol $\sigma$ is a function of entropy change of actual process [6]:

$$
\sigma=e^{(-\Delta s / R)}
$$

To do the calculations, rather than turbine geometry, amount of turbine rotational speed, stagnation temperature and pressure conditions of input flow to turbine are defined. Calculation will be started from turbine inlet. The solution of the flow equation through the suggested algorithm for modeling is as follows:

First, the proper Mach number is determined in blade cascade inlet. Then by using of continuity equation in turbine inlet, the mass flow rate is calculated. By guessing an initial Mach number and flow angle in blade outlet, losses coefficients and total loss coefficient will be determined by using of loss model. After determination the total loss coefficient, the only unknown parameter in the flow equation is outlet Mach number that is calculated. By calculating of outlet Mach number, the outflow angle will be modified and this repetition continued until intended precision achieved. By determining final outlet Mach number, another parameter like outlet stagnation pressure and temperature will be achieved.

Calculating the flow condition after choke, is one trait of done modeling. In blades, choking phenomenon occurs when Mach number or critical velocity ratio is equal one. For values of Mach number greater than 1.0, the outlet flow angle of the blade row is calculated by using of choking mass flow.

By using of flow equation and placement $M=1$, we reach to Eq. (3) for critical mass flow: 
$m_{c r}^{\square}=\cos \left(\alpha_{\text {out }}\right) \cdot \sigma \cdot A \cdot P_{0} \cdot\left(\frac{1+\gamma}{2}\right)^{\frac{-1}{(\gamma-1)}} \cdot \sqrt{\frac{2 \gamma}{R T_{0}(\gamma+1)}}$

The critical mass flow that is calculated in Eq. (3), is the choking mass flow, that its value is constant for $\mathrm{M}>1$.

$m_{\text {choke }}=m_{c r}$

For calculating the outlet flow angle in choking region, the choking mass flow is used $[7,8]$ :

$$
\cos (\alpha)=\frac{m_{\text {choke }}}{\sigma \cdot A \cdot P_{0} \cdot M\left(1+\frac{\gamma-1}{2} M^{2}\right)^{\frac{1+\gamma}{2(1-\gamma)}} \sqrt{\frac{\gamma}{R T_{0}}}}
$$

After calculation the Mach number, choking mass flow and flow angle, other required quantities are obtained like conditions before choke.

\subsection{Loss Coefficients}

Different energy losses that usually are considered in turbine, include profile loss, secondary loss, tip leakage loss and annulus loss. These losses in axial flow turbines are expressed in terms of loss coefficients. The loss coefficients manifested by a decrease in the stagnation enthalpy, and a variation in the static pressure and temperature, compared to the isentropic flow [9].

Enthalpy loss coefficient, entropy loss coefficient and pressure loss coefficient are three usual loss coefficients in turbines. We used the pressure loss coefficient and the enthalpy loss coefficient in our modeling that their equations are presented in this part.

The pressure loss coefficient defined as $[5,8]$ :

(a) For a nozzle (stator)

$Y_{N}=\frac{P_{01}-P_{02}}{P_{02}-P_{2}}$

(b) For a reaction stage (rotor)

$Y_{R}=\frac{P_{02, r e l}-P_{03, r e l}}{P_{03, r e l}-P_{3}}$

The enthalpy loss coefficient is given by:

(a) For a nozzle (stator)

$$
\zeta_{N}=\frac{h_{2}-h_{2 s}}{h_{01}-h_{2}}=\frac{T_{2}-T_{2 s}}{\frac{1}{2} C_{2}^{2}}
$$

(b) For a reaction stage (rotor) 


$$
\zeta_{R}=\frac{h_{3}-h_{3 s}}{h_{02, \text { rel }}-h_{3}}=\frac{T_{3}-T_{3 s}}{\frac{1}{2} W_{3}^{2}}
$$

The parameters and subscripts that are used in these equations, are based on diagram (enthalpyEntropy) in Fig. 1.

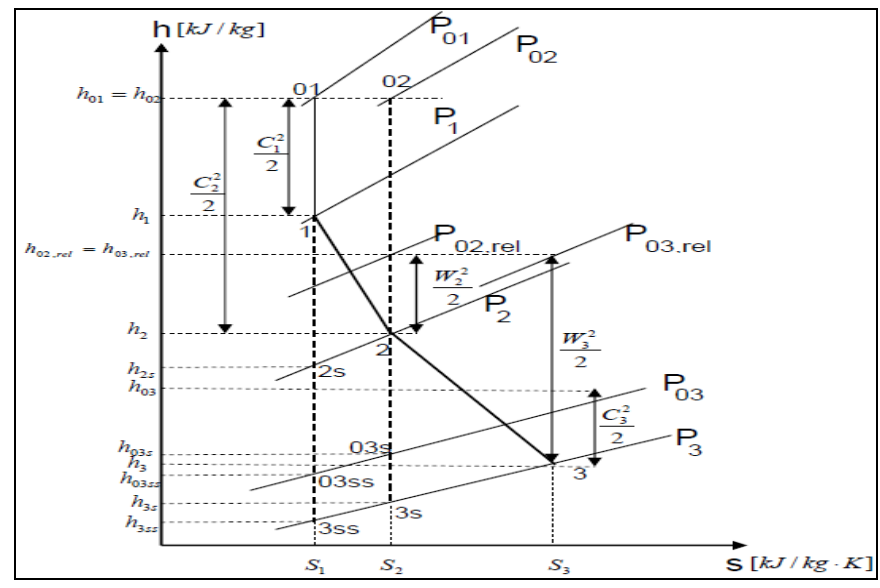

Fig. 1: h-s diagram

There are different loss models for predicting the amount of loss in the axial flow turbines. In this section three models of these losses have been presented.

\subsection{Soderberg's model}

This model is useful for obtaining quick and preliminary estimates of turbine performance.

Soderberg gave the total loss coefficient as:

$$
\begin{aligned}
& \zeta_{N}=\left(\frac{10^{5}}{\operatorname{Re}}\right)^{1 / 4}\left[\left(1+\xi^{*}\right)\left(.993+.075 \frac{l}{H}\right)-1\right] \\
& \zeta_{R}=\left(\frac{10^{5}}{\operatorname{Re}}\right)^{1 / 4}\left[\left(1+\xi^{*}\right)\left(.975+.075 \frac{l}{H}\right)-1\right]
\end{aligned}
$$

In these equations, $\zeta^{*}$ is the nominal loss coefficient and main function of blade deflection.

$$
\zeta^{*}=.04+.06\left(\frac{\varepsilon}{100}\right)^{2}
$$

Soderberg's model only includes profile and secondary flow loss but not tip clearance loss. The profile loss was considered mainly as a function of blade deflection. The secondary loss in this model depends mainly on the blade aspect ratio, $1 / \mathrm{H}$.

The neglect of some parameters like inlet boundary layer and the blade geometry renders Soderberg's loss model open to criticism [9]. 


\subsection{Kacker and Okapuu's developed model}

This model is the latest refinements proposed by benner et al. of kacker and okapuu,s model and Tournier \& Genk developed it, that we used in this research.

The total pressure loss coefficient in this model is given as:

$Y=\left(Y_{p}+Y_{s}\right)+Y_{T E}+Y_{T l}$

Benner et al. proposed a loss scheme for the breakdown of the profile and secondary losses as:

$\left(Y_{p}+Y_{s}\right)=\left(1-\frac{Z_{T E}}{H}\right) \times Y_{p}^{\prime}+Y_{s}^{\prime}$

The profile loss coefficient, based on recent turbine cascade data is given by:

$Y_{p}^{\prime}=.914 \times\left[K_{\text {in }} Y_{p, A M}^{\prime} K_{p}+Y_{\text {shock }}\right] \times K_{\mathrm{Re}}$

The factor Kp in Eq. (19) is identical to that introduced by Kacker and Okapuu[11] to account for the gas compressibility. $\mathrm{Y}_{\mathrm{p}, \mathrm{AM}}$ is the same profile loss that presented by Ainley \& Mathieson.

The shock losses, appearing in Eq. (19), are calculated as:

$Y_{\text {shock }}=.75\left(M_{\text {in }, H}-0.4\right)^{1.75}\left(\frac{r_{H}}{r_{T}}\right)\left(\frac{\rho_{\text {in }}}{\rho_{\text {out }}}\right) \frac{1-\left(1+\frac{\gamma-1}{2} M_{\text {in }}^{2}\right)^{\gamma / \gamma-1}}{1-\left(1+\frac{\gamma-1}{2} M_{\text {out }}^{2}\right)^{\gamma / \gamma-1}}$

In Eq. (20), Min,H is the inlet Mach number at the hub. It can be obtained from the correlation between the inlet average Mach number and the ratio of the hub radius to the tip radius [11].

The factor Kin $=2 / 3$, used by Kacker \& Okapuu, underpredicts the profile losses for blade rows with axial inflow. Zhu and Sjolander have introduced a Reynolds number correction factor based on their recent blade cascade data, as:

$$
\begin{array}{cl}
K_{\mathrm{Re}}=\left(\frac{2 \times 10^{5}}{\mathrm{Re}_{\text {out }}}\right)^{.575} & \text {, or } \mathrm{Re}_{\text {out }}<2 \times 10^{5} ; \\
K_{\mathrm{Re}}=1.0 & \text {, for } \mathrm{Re}_{\text {out }} \geq 2 \times 10^{5} ;
\end{array}
$$

The spanwise penetration depth $\left(\mathrm{Z}_{\mathrm{TE}}\right)$ of the separation line between the primary and the secondary loss regions, appearing in Eq. (18), is given by:

$\frac{Z_{T E}}{H}=\frac{.10 \times\left|F_{t}\right|^{79}}{\sqrt{\cos \alpha_{\text {in }} / \cos \alpha_{\text {out }}} \times(H / l)^{.55}}+32.7\left(\frac{\delta^{*}}{H}\right)^{2}$

$\delta^{*}$, is the boundary layer displacement thickness at the inlet endwall [11]. 
The tangential loading parameter, $F_{t}$, in Eq. (23) is given by:

$$
F_{t}=2 \frac{s}{l \times \cos \phi} \times \cos ^{2}\left(\alpha_{m}\right) \times\left(\tan \alpha_{i n}+\tan \alpha_{\text {out }}\right)
$$

The mean velocity vector angle is given by:

$$
\tan \left(\alpha_{m}\right)=\frac{1}{2}\left(\tan \alpha_{\text {in }}-\tan \alpha_{\text {out }}\right)
$$

The secondary loss coefficient in equation (23), is given by [12]:

(a) For $H / l \leq 2 / 0$

$Y_{s}^{\prime}=\frac{.038+.41 \times \tanh \left(1.2 \delta^{*} / H\right)}{\sqrt{\cos \phi} \times\left(\cos \alpha_{\text {in }} / \cos \alpha_{\text {out }}\right) \times\left(\frac{H}{l}\right)^{.55} \times\left(l \cos \alpha_{\text {out }} / l_{x}\right)^{.55}}$

(b) For $H / l>2 / 0$

$Y_{s}^{\prime}=\frac{.052+.56 \times \tanh \left(1.2 \delta^{*} / H\right)}{\sqrt{\cos \phi} \times\left(\cos \alpha_{\text {in }} / \cos \alpha_{\text {out }}\right) \times \frac{H}{l} \times\left(l \cos \alpha_{\text {out }} / l_{x}\right)^{.55}}$

The aspect ratio factor, $F_{A R}$, is a function of the blade aspect ratio (Chord/Height) [11].

In this model, the trailing edge loss coefficient, $Y_{T E}$, is a function of outlet Mach number and kinetic energy loss coefficient that its equation is presented by Kacker \& Okapuu.

The tip leakage loss coefficient, $Y_{T l}$, in turbine blades cascade is calculated using the approach of Yaras and Sjolander [13].

\section{RESULTS AND DISCUSSION}

In order to have a better understanding of the two stage axial flow turbine behaviour and verify the suggested algorithm accuracy, modeling has been done on this engine by using of two different loss model. Experimental data have been obtained from Ref. [14]. Also turbine blades geometry have been measured by authors.

Figs. 2 and 3 show variation of the turbine mass flow versus pressure ratio at design speed. The design speed is $38100 \mathrm{rpm}$ for compressor turbine (First Stage turbine) and $33000 \mathrm{rpm}$ for power turbine (Second Stage turbine). The conditions are the same as the experiments. The comparison of achieved results of modeling with experimental results shows that the theoretical values agree with the experimental values and good adaptation exist between these results.

In Figs. 4 and 5 efficiency curves of modeling were brought in design speed. Efficiency rises as increase of pressure ratio until it reaches its maximum measure. The reason for these changes is that in special cases, the incidence angle and energy losses due to it, reach its minimum value, so that in this condition the efficiency will maximize, and after this condition, the losses will increase again. 
In Figs. 6 and 7 the losses prediction have been shown. Fig. 6 is related to power turbine rotor blade and Fige. 7 is related to power turbine stator one.

In these Figures distribution of the profile loss, secondary loss, tip leakage loss, trailing edge loss, shock wave and total loss coefficient are presented. When the pressure ratio rises, the profile loss and total loss coefficient decrease and reach to a minimum point, and from there begin to increase again. But the Secondary loss, tip leakage loss and trailing edge loss almost exhibit linear behavior. Also this behavior reported by Ning Wei [9].

The profile loss has greatest value among another losses coefficient. The value of this loss, which is calculated with Eq. (14), give the lowest value near the pressure ratio 2.54 that this pressure ratio is related to about zero incidence.

In Fig. 8 Enthalpy loss coefficient is shown for rotor and stator of power turbine. As can be seen the measure of this loss for stator blade is greater than rotor blade. This is because, according to Eqs. (10) and (11) the enthalpy loss is a main function of the blade deflection.

In Table 1, a comparison between outlet pressure and temperature from turbine blades and experimental data are presented.

Table 1: Comparison between outlet pressure and temperature in theoretical and experimental Results

\begin{tabular}{|l|c|c|c|c|}
\cline { 2 - 5 } \multicolumn{1}{l|}{} & First Stage at 38100 rpm & \multicolumn{2}{c|}{ Second Stage at 33000 rpm } \\
\hline & Pout(Kpa) & Tout(k) & Pout(Kpa) & Tout(k) \\
\hline Experimental Data & 282.6 & 1058.15 & 111.00 & 901.15 \\
\hline soderberg's loss model & 302.8 & 1077 & 171.2 & 924.7 \\
\hline $\begin{array}{l}\text { Kacker and Okapuu's } \\
\text { developed loss model }\end{array}$ & 278 & 1070 & 124 & 866 \\
\hline
\end{tabular}

\section{CONCluding}

In this paper, one-dimensional modeling was done by using of suggested algorithm and different loss models on a typical two stage axial flow turbine, in order to validate the suggested method and loss models. According to the results of modeling, it is clear that this modeling and suggested algorithm, predict the turbine performances acceptably.

Comparing the results of these models show that Kacker and Okapuu's developed model gave the closest results to the reference data because this model estimated the loss coefficients with greater accuracy.

\section{FIGURES AND DRAWINGS}

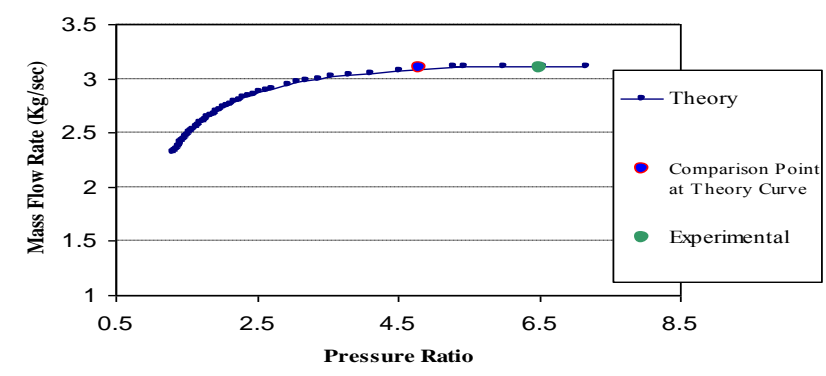


Fig. 2: Mass flow vs. Pressure ratio by using of Kacker and Okapuu's developed model

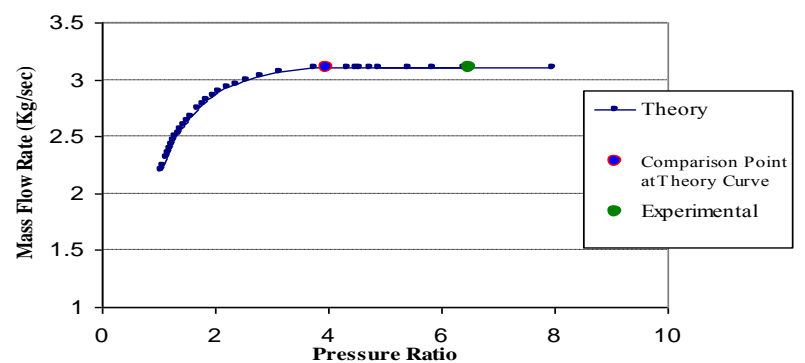

Fig. 3: Mass flow vs. Pressure ratio by using of soderberg's model

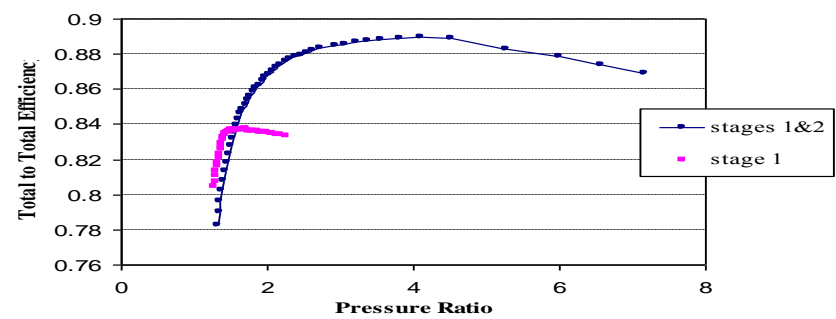

Fig. 4: Turbine efficiency vs. Pressure ratio by Kacker and Okapuu's developed loss model

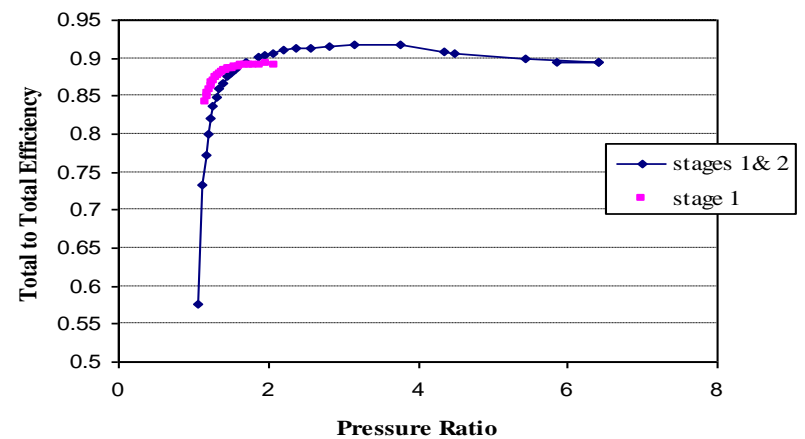

Fig. 5: Turbine efficiency vs. Pressure ratio by Soderberg's loss model

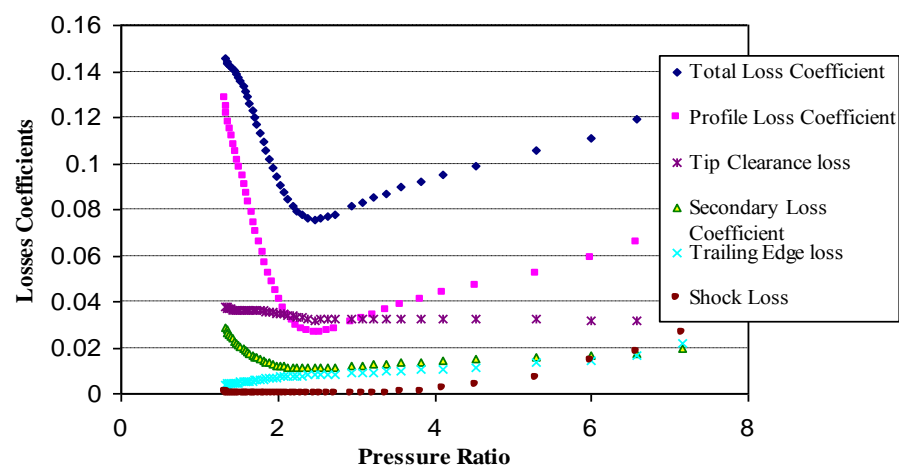

Fig. 6: Loss coefficients vs. Pressure ratio 


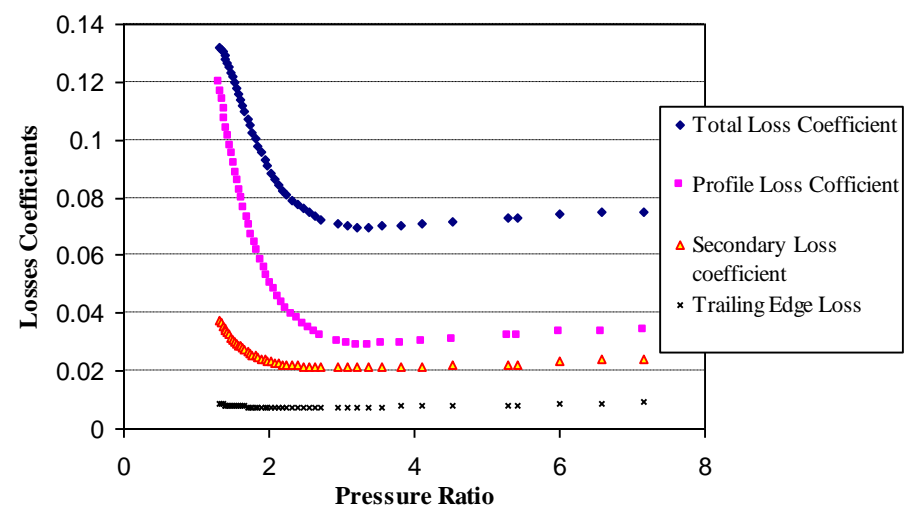

Fig. 7: Loss coefficients vs. Pressure ratio

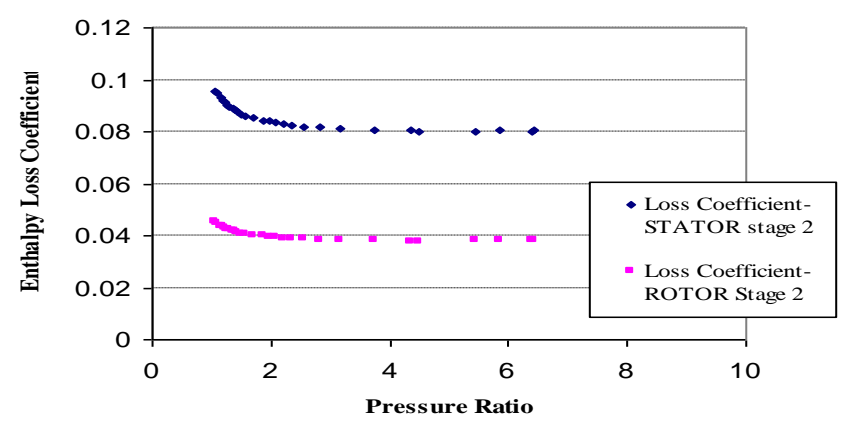

Fig. 8: Loss coefficients vs. Pressure ratio

\section{REFERENCES}

[1] Schobeiri M., Turbomachinery Flow Physics and Dynamic Performance, Texas A\&M University, 2005.

[2] Klepper J., Technique to predict stage-by-stage, Pre-Stall compressor performance characteristics using streamline curvature code with loss and deviation correlations, MS Thesis, University of Tennessee, Knoxvill, 1998.

[3] Horlock, J.H., "Axial Flow Turbines", University of Liverpol, Butterwoeth, London, 1966.

[4] Whitfield, A.; baines, N.C., "Design of radial turbomachines", Impeial college of science, London, 1990.

[5] Rao S.S. and Gupta R.S., Optimum design of axial flow gas turbine stage , part I: Formulation and analysis of optimization problem, ASME, journal of Engineering for Power, vol. 102, pp.782-789, 1980

[6] Whitfield A. and Baines N.C., Design of radial turbomachines, Impeial college of science, London, 1990

[7] Wasserbauer C.A. and Glassman A.J., Fortran program for predicting off-design performance of radial inflow Turbines, Nasa Report, D 8063, 1975.

[8] Glassman A.J., Turbine design and application, Nasa Report, N 95-22341,1994.

[9] Ning Wei, Significance of loss models in Aero thermodynamics simulation for axial Turbines, Doctoral Thesis, Royal Institute of Technology, Sweden , 2000.

[10] Cohen H., Rogers C. and H.Saravanamutto, Gas Turbine Theory, Longman group ,1996.

[11] Tournier J.M. and Genk M., Axial flow multi-stage turbine and compressor models, Journal of energy conversion and management, Vol. 51, PP.16-29, Elsevier 2009.

[12] Dahlquist A.N., Investigation of Losses Prediction Methods in 1D for Axial Gas Turbines, MS Thesis, Lund University, Sweden, 2008.

[13] Yaras M.I. and Sjolander S.A, Prediction of tip-leakage losses in axial turbines, Journal of Turbomachinary, Vol. 114, PP. 204-10, 1992.

[14] Deport Maintenance Work Requirement for Engine, Aircraft, Turboshaft Iran T400-WV-402, IRANIAN GROUND FORCES, AUGUST 1975. 


\begin{abstract}
Authors
Samak. Hosseinzadeh was born in August 22nd 1985 in Sari,Mazandaran. He is PhD student of mechanical field (energy conversion) at the Department of Mechanical Engineering, West Tehran Branch, Islamic Azad University, Tehran, Iran. He received his Ms. degree in mechanical engineering (Energy Conversion) from South Tehran Branch in 2010. He also received his BSc degree in thermal fluids from Islamic Azad University Sari Branch; Mazandaran in 2007.He did his military service in Manufacturing, Mining and Trade organization as an industry expert from 2010 to 2012. $\mathrm{He}$ is currently a university lecturer in Islamic Azad Universities in Mazandaran, Iran. The teaching courses included Mechanical technology, Automotive and Machinery, Power Plant Technology, Installation Technology, Chemical Industry, Architecture, Power Electronics, Project Management and Executive Management. He also was a Technical Office Manager (Head Office) in Nogostaran Construction Installation Company in Tehran from 2007 to 2011. He is a member of Iran Construction Engineering organization.
\end{abstract}

Doctor Ramin Ghasemi is a faculty member of Islamic Azad University, Department of Mechanical Engineering, West Tehran Branch, Islamic Azad University, Tehran, Iran. He received his Doctorate degree in mechanical engineering (Energy Conversion) from Tarbiat Modares University, Tehran,Iran. He is assistant professor. The teaching courses includes CFD, CONDUCTION, CONVECTION, RADIATION, AERODYNAMIC ,.. for PHD students.

Meghdad Rahimi Galogahi was born in Monday, July 2, 1979 in Behshahr, Mazandaran. He received his MS. degree in mechanical engineering, Energy conversion from Babol, Noshirvani University of Technology, Babol, Mazandaran in 2005 . He also received his BSc degree in thermal fluids from Babol, Noshirvani University of Technology, Babol, Mazandaran. He is currently faculty member of Islamic Azad University, Behshahr, Mazandaran, Iran. He is also the Managing Director and employer of produced Payab cartons. He is a member of Iran Construction Engineering organization.

Amin. Bahrami was born in September 22nd 1986 in Gorgan, Golestan. He received his MS. degree in mechanical engineering, Energy conversion From Iran University of Science and Technology in 2010. He also received his BSc degree in thermal fluid from Azad Islamic University Sari Branch, Mazandaran. He did his military service in Organization of School Renovation, as a mechanical engineering expert from 2010 to 2011. He is currently university lecturer in Islamic Azad Universities in Golestan, Iran. Also, he is an employer in Organization of School Renovation. He is a member of young researchers club in Iran and Iran Engineering Organization Structure too. Hi was chosen as the top student at the Iran University of Science and Technology in 2010 and as an undergraduate student, he was elected second.
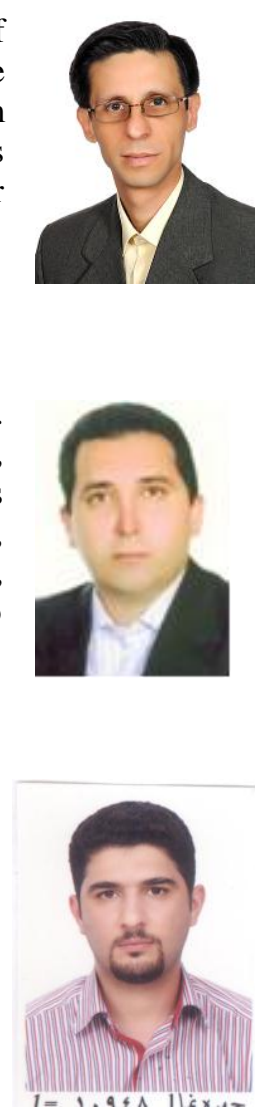